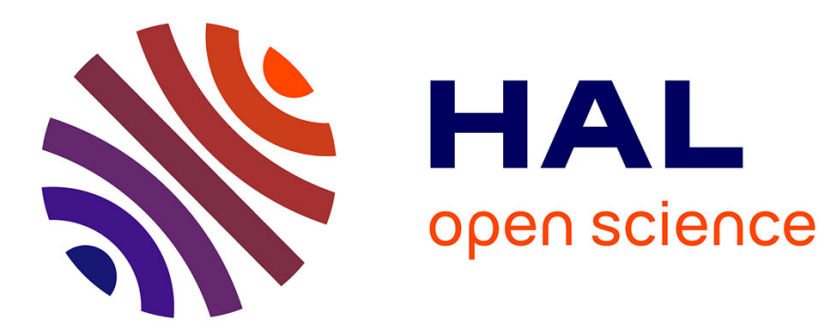

\title{
Le statut matrimonial de la femme dans l'islam médiéval à l'épreuve des documents juridiques
}

Moez Dridi, Muriel Roiland

\section{To cite this version:}

Moez Dridi, Muriel Roiland. Le statut matrimonial de la femme dans l'islam médiéval à l'épreuve des documents juridiques. Hawwa, 2019, 17 (2-3), pp.231-256. 10.1163/15692086-12341358 . halshs02390890

\section{HAL Id: halshs-02390890 \\ https://shs.hal.science/halshs-02390890}

Submitted on 3 Dec 2019

HAL is a multi-disciplinary open access archive for the deposit and dissemination of scientific research documents, whether they are published or not. The documents may come from teaching and research institutions in France or abroad, or from public or private research centers.
L'archive ouverte pluridisciplinaire HAL, est destinée au dépôt et à la diffusion de documents scientifiques de niveau recherche, publiés ou non, émanant des établissements d'enseignement et de recherche français ou étrangers, des laboratoires publics ou privés. 


\title{
Le statut matrimonial de la femme dans l'islam médiéval à l'épreuve des documents juridiques
}

\author{
Moez DRIDI \\ UMR Orient \& Méditerranée-CNRS \\ rdridi@QNL.QA \\ Muriel ROILAND \\ Institut de Recherche et d'Histoire des Textes-CNRS \\ muriel.roiland@irht.cnrs.fr
}

\begin{abstract}
In the dār al-islām, a juristic and contractual conception of the institution of marriage prevailed. Marriage was indeed considered as a contract that set the rights and duties of the spouses. On the basis of legal documents written between the third/ninth and the tenth/sixteenth centuries, and coming from different parts of the Arabic world, we examine women's legal entitlements in marriage contracts, notably with regard to dot dispositions (șad̄q), and stipulations pertaining to conjugal relationships (shurūt).

During the married life, a succession of private law contracts can be concluded by the spouses: marriages, receipt of the dowry, repudiation or divorce. The corollary is that some women do not hesitate to request a $q \bar{a} d \underline{l}$ to enforce the clauses they, or their representative, have written in the legal documents.
\end{abstract}

\section{Keywords}

Medieval Islam - history of family law - fiqh - women - marriage - zawāj - dowry - marital relations.

\section{Résumé}

Dans le dār al-islām, c'est une conception juridique et contractuelle du mariage qui prévaut : le mariage y est en effet un contrat qui fixe les droits et les obligations des époux. 
Sur la base d'un corpus de documents juridiques rédigés entre le $\mathrm{III}^{\mathrm{e}} / \mathrm{IX}^{\mathrm{e}}$ et le $\mathrm{X}^{\mathrm{e}} / \mathrm{XVI}^{\mathrm{e}}$ siècle, à partir de cas provenant de plusieurs régions du monde arabe, nous mettons ici en valeur la situation matrimoniale des femmes, en particulier la valeur de la dot, les relations conjugales et l'ajout éventuel aux contrats de conditions qui leur sont favorables.

La vie de couple peut en effet être rythmée par une succession d'actes de droit personnel : mariages, quittances de réception de la dot, répudiation ou divorce. Le corollaire étant que certaines femmes n'hésitent pas à saisir le $q \bar{a} d \underline{l}$ pour faire respecter les clauses qu'elles, ou leur représentant, ont fait inscrire dans les contrats.

\section{Mots clés}

Islam médiéval - histoire du droit de la famille - fiqh - femmes - mariage - zawāj - dot relations conjugales.

Dans l'Islam médiéval, le mariage conjugue des aspects religieux, d'ordre politique, économique et social mais c'est le cadre juridique qui prévaut puisqu'il y est avant tout question d'un contrat qui fixe les droits et les obligations des époux. C'est aussi un rite qui fait entrer chaque partenaire dans la vie conjugale, avec des conséquences différentes pour les femmes et pour les hommes.

Les juristes du dār al-islām ont longtemps débattu des questions concernant le droit de la famille, notamment du mariage. Les historiens qui, dès le XIX ${ }^{\mathrm{e}}$ siècle, ont étudié les sociétés musulmanes dans un contexte colonial avaient ainsi à leur disposition des ouvrages de fiqh et des recueils de fatāwā, ces réponses juridiques proposées par les muftis en réponse à des questions de droit posées par des juges ou des fidèles afin d'éclairer leurs décisions. Bien qu'ils aient eu connaissance de la pratique judiciaire de leur époque, ces savants traitaient principalement des aspects théoriques sans toujours chercher à départager ce qui relevait des coutumes et du droit musulman. Certains, comme Georges-Henri Bousquet ou Marcel Morand ${ }^{1}$, ont repris l'avis de certains fuqahā', établissant une analogie formelle entre le contrat de mariage et le contrat de vente : la femme représentait la chose vendue et la dot en

Georges-Henri Bousquet, Précis de droit musulman, 2 vol. (Alger, Maison des livres, 1935), 1, 39-64 ; Marcel Morand, Etudes de droit musulman algérien, 2 vol. (Alger : Typ. A. Jourdan, 1910), 1, 113-27. 
constituait le prix ${ }^{2}$. Quant à la dissolution du mariage, la répudiation unilatérale par le mari était selon eux courante et le «divorce par consentement mutuel $»^{3}$ une règle juridique inappliquée. Les conclusions auxquelles ils aboutissent montrent bien que les documents de la pratique juridique étaient alors rarement exploités.

Or, il s'agit d'un riche corpus dont le contenu à la fois dense et varié nous éclaire sur la vie maritale, ainsi que sur le statut et le rôle, déterminant, de la femme dans le dār al-islām à l'époque médiévale. La rareté des études comparatives entre textes historiques, traités de droit musulman, recueils de fatāwa et documents de la pratique juridique, explique en partie la déconnexion entre les travaux consacrés à la femme et à l'institution du mariage et les études sur l'histoire des sociétés médiévales en terre d'islam. L'analyse de ces documents permet pourtant d'éclairer certains aspects de la réalité historique, sociale et juridique des femmes ${ }^{4}$.

C'est l'objectif que nous nous fixons, sans entrer dans le détail de l'histoire de l'institution sociale et juridique du mariage, déjà largement abordé sous des angles différents ${ }^{5}$. À partir d'un corpus de documents juridiques allant $\mathrm{du} \mathrm{III} / \mathrm{IX}^{\mathrm{e}}$ au $\mathrm{X}^{\mathrm{e}} / \mathrm{XVI}^{\mathrm{e}}$ siècle réunis dans la base de données CALD (Comparing Arabic Legal Documents) ${ }^{6}$ - plus précisément dans une quarantaine de contrats de mariage et une vingtaine de contrats de divorce contractés pour la plupart en Égypte, dans le Bilād al-Shām, en Ifrīqiyā et en al-Andalus - nous proposons ici une nouvelle approche pour mettre en valeur certains aspects du mariage et de la situation matrimoniale des femmes en Islam.

2 Georges Dumézil a défini quant à lui trois grandes formes de mariage : le rapt de la fiancée, l'amour et l'achat, dans Mariages indo-européens, Paris, Payot, 1979.

3 Le terme arabe: hul' implique une séparation à l'initiative de l'épouse et acceptée par son conjoint.

4 La propriété d'une maison, de terrains ou d'un esclave, une reconnaissance de dette, le montant d'une dot, un inventaire après décès, pour ne citer que quelques exemples. Les actes juridiques sont une preuve écrite qui permet aux contractants de se prévaloir d'un droit.

5 Par exemple: Thierry Bianquis, La famille arabe médiévale (Bruxelles, Complexe, 2005) ; Yossef Rapoport, Marriage, money and divorce in medieval Islamic society (Cambridge, Cambridge University Press, 2005); Kecia Ali, Marriage and Slavery in Early Islam (Cambridge, Mass, Harvard University Press, 2010); Mohammed Hocine Benkheira, Avner Giladi,Catherine Mayeur-Jaouen et Jacqueline Sublet, La famille en islam d'après les sources arabes (Paris, Les Indes savantes, 2013).

6 Base de données constituée dans le cadre du projet européen «Islamic Law Materialized», dirigé par Christian Müller de 2009 à 2013 et dont nous étions membres. 
Le fonds-CALD nous confronte en effet aux clauses utilisées par les notaires à l'époque médiévale et aux concepts auxquels elles font référence ${ }^{7}$.

Dans leur rédaction, à l'instar des autres contrats, les contrats de mariage suivent les exigences formulées par le droit musulman ( $f i q h)$ élaboré dans les quatre écoles juridiques principales, notamment dans les manuels notariés $(k u t u b \text { al-shurūt })^{8}$. Nous mettrons tout d'abord l'accent sur quelques éléments linguistiques en lien avec des textes de nature juridique avant de proposer une relecture des relations conjugales à travers quelques contrats pour comprendre suivant quel modèle et sur la base de quelles règles juridiques ils ont été rédigés.

Relevons tout d'abord les principaux éléments, d'ordre monétaire ou matériel qui déterminent la validité d'un contrat de mariage, en particulier le «présent nuptial » $(\text { sada } q)^{9}$. Remis à la femme par son futur époux selon des modalités déterminées, cette dot est le seul aspect matériel systématiquement présent dans tous les contrats de mariage. Elle est également parfois mentionnée dans les actes de divorce. On verra plus loin l'importance du șadāq, sa valeur et sa symbolique. D'autres éléments contribuent à la structuration de cet engagement matrimonial, mais sans qu'ils soient considérés comme des conditions fondamentales sous peine d'invalidité. C'est le cas notamment des règles de conduite conjugale fondée sur l'entretien de bons rapports : ḥusn al-mu 'āshara wa-l-suḥba.

Un autre aspect singulier caractérise certains documents et a soulevé un débat entre les juristes de différentes écoles : les conditions imposées par la femme lors de la signature du contrat $^{10}$, notamment l'obligation de vivre dans sa région natale. Le mari accepte que figure cette formule juridique : «il s'est imposé de respecter ses engagements » (sharaṭa fulān shurūtan awjabahā 'alā nafsihi) ${ }^{11}$.

\footnotetext{
$7 \quad$ Les documents conservés dans la base CALD sont en majorité édités. Les documents inédits sont pour l'essentiel d'origine maghrébine et andalouse. Le plus ancien contrat de mariage exploité dans cet article est probablement daté de 222/836. Abū Nașr Muhammad al-Samarqandī, Kitāb al-shurūṭ wa-'ulūm al-ṣukūk, éd. M. Jāsim alHadīthī (Bagdad, 1987).

9 Nous adoptons ensuite le mot dot, même si en français le terme désigne principalement ce que l'épouse apportait en se mariant. (Madrid, Consejo Superior de Investigaciones Científicas, 1998), «Fuentes arábico-hispanas, $23 », 21-22$ et 109, par exemple.

11 Voir le document du Caire édité par Adolf Grohmann, Arabic papyri in the Egyptian library, Volume I : Protocols and Legal Texts with Twenty Plates (Le Caire, Egyptian Library Press, 1934), 85-8, trad. 89-91.
} 
Dans les contrats de mariage rédigés par les notaires, de nouvelles expressions apparaissent à partir $\mathrm{du} \mathrm{IV}^{\mathrm{e}} / \mathrm{X}^{\mathrm{e}}$ siècle, qui mettent en valeur les qualités de la future épouse sous forme d'adjectifs épithètes: «chaste» (al-'afífa), «jeune» (al-shābba), «perle protégée » (al-durra al-maknūna $)^{12}$ 《généreuse » (al-karīma), «femme parfaite » (al-mar'a $a l-k \bar{a} m i l)^{13}$. Kāmil est ici compris dans le sens de la dignité de la future épouse. Une remarque : l'adjectif kāmil est ici au masculin. Cette règle grammaticale de «l'école » de Kūfa s'applique dans le cas où l'adjectif qualifie la femme par quelque chose qui lui est propre, et qui ne concerne en aucune manière l'homme ${ }^{14}$. De la même manière, on parle de imra'a țāliq, non țāliqa, parce que le tạlaq est une prérogative de l'homme seul, ou encore imra'a hâmil pour désigner la femme enceinte ${ }^{15}$. Dans le Coran, l'expression imra'a 'āqir désigne la femme de Zaccharie qui ne peut plus enfanter en raison de son âge (XIX, 5).

al-'afifa

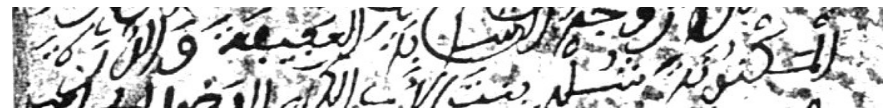

Madrid, Bibliothèque nationale, ms. 4908

(GR 72)

$931 / 1524$ al-kāmil

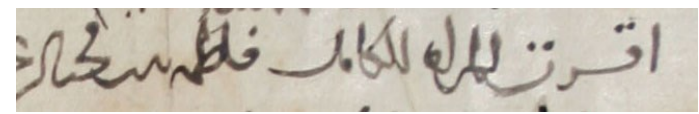

Jérusalem, Musée du Haram al-Sharīf

ms. 102

$789 / 1387$

\section{Du droit à la réalité historique : les conditions de validité du mariage}

Tout contrat entre deux ou plusieurs personnes respecte une structure par laquelle la volonté de chaque partie est exprimée. La validité du contrat dépend de la présence d'éléments constitutifs essentiels (arkān) que l'on retrouve dans les contrats de mariage, rédigés par les notaires en présence de témoins : - la mention du nom des conjoints, l'époux et l'épouse, ainsi

\footnotetext{
12 Voir le contrat de 931/1524 édité par Wilhelm Hoenerbach dans Spanisch-Islamische Urkunden: aus der Zeit der Nasriden und Moriscos (Berkeley, Los Angeles, University of California Press, 1965), 1, 189-91, $\mathrm{n}^{\circ}$ 13. La jeune épouse est originaire de Calatayud (al-Andalūs). Ces termes ont disparu des actes notariés d'époque contemporaine. Voir les travaux de Dalenda Largueche sur les femmes en Tunisie à l'époque moderne, notamment Monogamie en Islam : l'exception kairouanaise (Tunis, Manouba, Centre de publication universitaire, 2011).

14 Ibn Qutayba n'associe pas cette règle à « l'école » de Kūfa : voir son chapitre intitulé « Bāb awșāf al-mu'annath bi-ghayr al-hā' » dans Adāb al-kātib (Beyrouth, Dār al-kutub al-'ilmiyya, 1988).

15 Nous remercions Lahcen Daaif pour l'explication de ce point grammatical. Voir par exemple la racine $H M L$ dans le Lisān al-'arab.
} 
que du tuteur matrimonial (walī), dont la présence peut conditionner la validité du contrat : c'est le cas par exemple de jeunes filles vierges (bikr) ou impubères (jāriya). Ceux qui peuvent se prétendre tuteur d'une femme de condition libre sont le père, le grand-père, le fils, le petit-fils, voire le maître ayant affranchi son esclave ou encore le représentant de l'autorité désigné à cet effet, comme un cadi ou son remplaçant. Le mariage n'est pas valable si la femme a consenti elle-même à son mariage ou par le biais d'un mandataire qu'elle a désigné et qui ne serait pas son wal̄ légal ${ }^{16}$. En l'absence de walī, le mariage est donc considéré comme nul ( fāsid) ou inexistant (bātili). Quant à la femme déflorée (thayyib), « dès l'instant où elle est majeure (pubère), il lui est loisible de se passer de l'entremise de ce dernier ». L'école hanafite va plus loin en considérant formellement qu'une femme pubère a le pouvoir de contracter un mariage sans l'intermédiaire d'un tuteur mais ses parents conservent le droit de contester devant le juge le mariage en cas de mésalliance ${ }^{17}$.

Pour que le contrat soit valide, les écoles shafiite et hanbalite exigent l'emploi du mot zawāj ou du terme nikạh ou encore de verbes dérivés de ces deux substantifs. Ils doivent figurer tant dans le texte de la demande que dans celui de l'acceptation ${ }^{18}$.

Le mariage étant un contrat purement consensuel, l'échange des consentements (ījāb et qabūl) est l'élément sine qua non du mariage. Il n'existe aucune divergence entre les juristes sur cette condition ${ }^{19}$.

Un autre fondement est la présence de deux témoins réglementaires. Les juristes utilisent la formule : «le mariage ne peut être conclu (lā yan'aqid) sans témoins ». Ces derniers doivent avoir certaines qualités et être présents au moment de l'échange des consentements, donnant ainsi au mariage un caractère public. Cette diffusion (tashhīr) est manifeste dans la formulation même du contrat. Ainsi, l'emploi systématique de la nisba (nom de relation) des deux contractants et des témoins traduit une appartenance familiale, tribale ou régionale bien précise. L’énoncé des différents éléments du nom des témoins signataires permet aussi d'éviter toute confusion homonymique qui pourrait être la cause

\footnotetext{
16 Le tuteur matrimonial ou son représentant $\left(n \bar{a}{ }^{\prime} i b\right)$ dit : «je te donne en mariage » ou : «je te donne pour épouse ».

17 Muḥammad b. Aḥmad al-Sarakhsī, Kitāb al-Mabsūṭt, éd. Muhammad Rāọ̄i (Le Caire, Maṭba'at alSa‘āia, 1906-13), 30 t. en 15 vol., 5, 10. Muhammad b. Aḥmad Ibn Juzayy, al-Qawān̄̄n al-fiqhiyya, éd. ‘Abd Allāh al-Minshāwī (Le Caire, Dār al-ḥadìth, 2005), 175.

19 Muwaffaq al-Din 'Abdallāh b. Aḥmad Ibn Qudāma, Le précis de droit d'Ibn Qudāma, jurisconsulte musulman d'école hanbalite né à Jérusalem en 541/1146, mort à Damas en 620/1223, (Beyrouth, 1950), trad. fr. par Henri Laoust, 170.
} 
d'une démarche auprès d'un cadi. Il se peut cependant qu'après une dizaine d'années, à la suite de la mort de l'un des témoins ou du fait de la perte du contrat, les époux en signent un nouveau, reprenant l'intégralité des données du, ou des actes précédents, afin de conserver les droits de chacun des époux. Le notaire précise alors dans le contrat que les témoins les « connaissent de visage, de nom, de lignée et de condition (nasab wa-hasab) ${ }^{20}$.

De plus, on voit que l'épouse qui donne son consentement, de son propre chef ou par l'intermédiaire d'un représentant légal doit être adulte et saine d'esprit et de corps (saḥiḥat al'aql wa-l-badan/jism $)^{21}$. À ces conditions s'ajoute parfois, et de manière non systématique, l'indication qu' « il n'existe aucun empêchement légal à l'encontre de la mariée » (khāliya min al-mawāni، al-shar'iyya) ${ }^{22}$. Les témoins confirment dans ce cas l'authenticité de cette information et précisent que la femme est libre de tout autre engagement conjugal $\left(k h u l u w w u h a \bar{a}\right.$ min $\left.a l-z a w \overline{a j}{ }^{23}\right)$. Le contrat s'achève par l'obligation d'une lecture de la totalité du contenu écrit, mot à mot (harfan harfan), en présence non seulement du mari et des témoins mais aussi de la femme. Enfin, les deux époux reconnaissent ainsi avoir pris connaissance et avoir compris, sans contrainte ni oppression, les différentes clauses de leur engagement mutuel.

20 Voir les contrats de mariage d’Uqlūl récemment publiés par Yūsuf Rāghib, Transmission de biens, mariage et répudiation à Uqlūl, village du Fayyoum au $V^{e} / X I^{e}$ siècle (Le Caire, Cahier des Annales islamologiques 33, 2016), 56 notamment.

Nous trouvons parfois la formule suivante: Kämilat al-'aql wa-jā'izat al-amr lahā wa-'alayhā (...jouissant pleinement de ses facultés mentales et juridiquement capable de recevoir et de disposer » : il s'agit ici de sa capacité juridique. Voir Rāghib, Transmission de biens (Le Caire, 2016), 56. L'empêchement physique est généralement en lien avec des maladies sexuelles ou chroniques, telle la lèpre. Cette question est traitée dans les ouvrages de fiqh au chapitre des 'uyūb (vices). Il existe de nombreux cas d'empêchements légaux (mawāni ${ }^{\circ}$. Ce sont tous les cas dans lesquels une femme ne peut se marier, ponctuellement - par exemple si le délai de la 'idda n'est pas achevé en cas de répudiation ou de veuvage - ou définitivement, il s'agit là d'empêchements matrimoniaux, par exemple la parenté de lait et l'alliance. Voir par exemple, Mohammed Hocine Benkheira, «Alliance, symétrie et différence des sexes. Un problème d'exégèse juridique : la prohibition de la belle-mère et de la belle-fille », Islamic Law and Society 13/2 (2006) : 153-207.

23 Michel Mouton et alii, Mariage et séparation à Damas au Moyen Age. Un corpus de 62 documents juridiques inédits entre 337/948 et 698/1299 (Paris, Académie des Inscriptions et Belles Lettres, 2013), 147-8. 


\section{La dot : entre valeur matérielle et dimension symbolique}

La dot est, on l'a dit, l'unique condition matérielle imposée par tous les juristes dans la mesure où il s'agit d'une prescription coranique. Désignée par les termes mahr ou sadāq ${ }^{24}$, elle est donc un fondement (rukn) de la validité du mariage (min shurūṭ al-ṣiḥha). Les contrats de mariage débutent tous par hadha mā aṣdaqa et le terme șadāq est le plus souvent utilisé : on trouve 194 occurrences du terme șadāq pour 69 utilisations du mot mahr dans l'ensemble des documents de la base CALD.

Le mari a l'obligation de payer la dot, comme il est tenu de pourvoir à l'entretien de son épouse ${ }^{25}$. La dot peut aussi être un esclave ou l'affranchissement d'un esclave ${ }^{26}$. Son montant est laissé à la volonté des contractants et de leurs familles. Si le minimum est prévu en référence à des hadiths du Prophète ${ }^{27}$, aucune limite maximum n'a été fixée ${ }^{28}$. Une partie du montant est versée au comptant (maqbūọ). L'autre partie, le reliquat (al-mu'ajjal min dhalika), est versée ultérieurement selon des modalités qui sont précisées dans certains contrats, d'autres n'en faisant pas état. Le paiement de cette portion différée, connue aussi sous le nom de mu'akhkhar ou kāll (payable à terme), s'effectue de différentes manières ${ }^{29}$. Parfois la femme ou son tuteur imposent les conditions du versement par une formule telle que : «wa-akharat șadāqiha 'alā zawjiha [...] khams sīnina» (le reliquat de la dot à son

\footnotetext{
$24 S$ Sadāq fait référence au terme coranique șaduqa - comme dans Coran IV : 4. Mahr est mentionné dans les documents depuis 140-160/757-776 : voir Geoffrey Khan, Arabic Documents from early Islamic Khurasan, Studies in the Khalili Collection, vol. V (Londres, The Nour Foundation, 2007), 144 et 150. Les deux termes, mahr et șadāq sont à l'évidence utilisés de façon différente selon les contextes. En témoigne l'article de R. Idris, «Le mariage en Occident musulman d'après un choix de fatwās médiévales extraites du Mi 'yār d'al-Wanšarīsī », Studia islamica 32 (1970) : 157-67. Mahr est aussi utilisé dans le sens de présent nuptial.

La dot est tout ce qui peut constituer valablement une contrepartie licite et monnayable, à l'exception de l'alcool ou du porc.

C'est le cas de Safiya, une femme juive de Médine, à laquelle le Prophète donna en dot son affranchissement. Ibn Hanbal et Ibn Dāwūd se sont opposés à ce type de șadāq. Voir Ibn Juzayy, al-Qawāninn al-fiqhiyya (Le Caire, Dār al-ḥadīth, 2005), 175.

Hadith rapporté par Bukharī : «...Fût-ce une bague en fer », El-Bokhârî, Les traditions islamiques, 4 vol., trad. O. Houdas (Paris, 1908), III, 573. Ibn Saḥnūn dit que ce montant minimum est de 1/4 de dinar ou 3 dinars en argent : Kitāb al-ajwiba (Beyrouth, Dār Ibn Ḥazm, 2005), 137.

Si la valeur de la dot n'a pas été fixée lors de la conclusion du contrat, la future épouse peut demander l'ajout du montant avant la consommation du mariage (al-dukhül). En cas de désaccord, le cadi peut le fixer (mahr al-mithl) en fonction du rang social de l'épouse. Voir la thèse de doctorat soutenue à l'EPHE en janvier 2016 par Ziyad elsayed Farrouh, Le mahr (don nuptial) dans le droit islamique selon les écoles sunnites, chiites et ibadite. Le délai de ce paiement ne peut pas excéder 40 ans d'après Ibn Juzayy.
} 
épouse $[. .$.$] dans 5$ ans $)^{30}$. C'est ici l'épouse qui accorde ce délai ${ }^{31}$. Dans un contrat signé en 604/1207 en Égypte, la jeune fille, Khabā' bint Khalīfa al-Bahnasāwi $\overline{1}^{32}$ impose à son mari, le marchand 'Īsā b. Abī l-Fạ̣l, de lui payer vingt-cinq dinars au moment de la conclusion du contrat, le reste de la dot étant échelonné sur 12 ans et 16 mois $^{33}$ avec une moyenne de 2 dinars payables à la fin de chaque année. Le versement échelonné du reliquat est l'occasion d'actualiser les rapports au sein du couple. Il peut soit resserrer les liens familiaux, soit être source de conflit, voire de divorce, ce que l'on constate à travers différents type de contrats ${ }^{34}$. Ce reliquat actualise la plupart du temps le statut foncier de la femme ainsi que celui de ses descendants. C'est là un élément décisif de la relation contractuelle entre époux. D'après les fatāwa d'al-Wansharīsī, le reliquat constituait une source de revenu non négligeable pour la femme et toute sa famille, notamment dans les milieux ruraux ${ }^{35}$. La partie de la dot payable à terme pouvait par exemple consister en bestiaux, la femme pouvait donc en tirer profit en la transformant en capital, complément de ressources qu'elle utilisait comme bon lui semblait, dans l'intérêt de la famille.

La première partie de la dot payable au comptant à la femme ou à son tuteur $(\text { wali })^{36}$, représente, sur la base de notre corpus, l'équivalent du quart, voire parfois du tiers de la somme totale ${ }^{37}$. L'épouse ou son tuteur, dès réception de la première partie de la dot, signe en

\footnotetext{
$30 \quad$ On trouve l'expression dès le début $\mathrm{du} \mathrm{III}^{\mathrm{e}} / \mathrm{IX}^{\mathrm{e}}$ siècle. Voir Michael Thung, Arabische juristische Urkunden aus der Papyrussammlung der oesterreichischen Nationalbibliothek, Corpus Papyrorum Raineri XXVI (Leipzig, Generaldirektion der Oesterreichischen Nationalbibliothek, 2006), 14. Document édité par Grohmann, Arabic papyri (Le Caire, Egyptian Library Press, 1934), 1, 82-4, trad. p. 84-5.

32 Le père, Khalīfa est bazzāz (marchand d'étoffes de toutes espèces). Il s'agit d'un mariage arrangé dans le même milieu. Ce contrat est édité par Albert Dietrich, Eine Arabische Eheurkunde aus der Aiyubidenzeit (Berlin, Vorgelegt in der Sitzung der Deutschen Akademie der Wissenschaften zu Berlin vom: 30.11.1950, 1952), 125-6.

33 La durée est ainsi mentionnée dans le document.

34 C'est le cas d'une requête auprès d'un cadi à propos d'une dot, effectuée à l'époque bouride : Mouton et alii, Mariage et séparation à Damas au Moyen Age (Paris, Académie des Inscriptions et Belles Lettres, 2013), 149-52.

35 Dans la requête précitée, la dot de l'épouse était constituée de cent moutons, vingt chèvres, une jument, une paire de bœufs.... évalués à 12 dinars : voir Mouton, Mariage et séparation à Damas (Paris, Académie des Inscriptions et Belles Lettres, 2013), 147-8. Dans quelques documents, nous trouvons la mention : «qu'il [walī] doit la donner à sa fille ou à la femme qu'il lui est demandé de représenter (wa-'alayhi 'iṣăluhu ilayhā ». Voir le contrat signé en 604/1207 conservé à Hambourg et édité par Albert Dietrich dans Eine Arabische Eheurkunde aus der Aiyubidenzeit (Berlin, 1952), 121-54.

D'après les travaux menés par Shelomo Dov Goitein, A Mediterranean society: the Jewish communities of the Arab world as portrayed in the documents of the Cairo Geniza, 6 vol. (Berkeley, University California Press, 1967-93), 3, 122. Yusūf Rāghib précise qu'en Égypte et selon l'usage ('urf), le paiement de la moitié de la dot prédominait et qu'elle était réglée au comptant au moment de la signature, voir Rāghib, Transmission de biens (Le Caire, 2016), 50.
} 
présence de deux témoins, une quittance de réception de celle-ci (barā' dimma) portant la mention : «elle le tient pour quitte : abra'athu $\operatorname{minh}^{38}$ ». Cette quittance figure généralement en bas ou au verso du contrat de mariage ${ }^{39}$. Il est de l'intérêt de l'épouse de reconnaître par un écrit la réception de chaque versement afin d'éviter des tromperies de la part du mari qui peut affirmer avoir versé un montant au lieu d'un autre.

La vie de couple est ainsi réglée par une succession d'actes de droit personnel : mariages, quittance de réception des versements de la dot par l'épouse, mais aussi répudiation et divorce. Ces actes peuvent figurer sur un seul et même document. La femme le conserve précieusement comme preuve à présenter en cas de conflit, de divorce ou du décès de son mari. C'est ce que fait Zumurrud, esclave affranchie, dans un document qui contient sept actes la concernant, tous rédigés à Jérusalem en moins de trois ans, du 12 rajab 791/10 février 1389 au 15 dhū l-qa'da 793/15 octobre 1391). ${ }^{40}$ On a ici ses trois contrats de mariage, la mention $\mathrm{du}$ divorce, à son initiative ${ }^{41}$, avec son premier époux, et l'acte de répudiation par son deuxième mari. Dix mois plus tard, celui-ci atteste qu'il lui a versé une partie de sa dot et lui cède les biens acquis pendant leur mariage. La troisième union de Zumurrud devant un juge hanafite fait l'objet du dernier document. Le juge shafiite de Jérusalem y valide neuf mois plus tard le mariage, sans doute pour empêcher une éventuelle contestation de celui-ci. La suite du récit de sa vie matrimoniale ne nous est malheureusement pas parvenue, mais ce document soulève à lui seul bien des questions juridiques ${ }^{42}$. Zumurrud, qui se présente sans tuteur légal, affirme par exemple dans deux contrats de mariage qu'elle a bien respecté le délai de viduité légal de trois mois avant de s'unir à un nouveau mari, ce qui est à l'évidence

\footnotetext{
38 L. Daaif, «La barā'a : réflexions sur la fonction et l'évolution de la structure de la quittance ( $\mathrm{I}^{\mathrm{er}}$ $\mathrm{V}^{\mathrm{e}} / \mathrm{VII}^{\mathrm{e}}-\mathrm{XI}^{\mathrm{e}}$ siècles) » Annales islamologiques 48/2 (2014) : 3-60.

Voir la reproduction de ce contrat à la fin de l'article.

Donald Little, A Catalogue of the Islamic Documents from al-Haram aš-Šarīf in Jerusalem (Beyrouth, 1984), 305 ; documents en cours d'édition.

${ }^{41}$ Il s'agit d'une procédure au cours de laquelle, à l'issue d'une négociation, la femme rachète sa liberté en restituant le mahr et souvent en rajoutant de l'argent. Le khul' était la règle dans la société mamelouke: Rapoport, Marriage, Money and Divorce in Medieval Islamic Society (Cambridge, Cambridge University Press, 2005), 72-3.

42 Les données concernant Zumurrud et ses trois maris sont insuffisantes pour tirer des conclusions juridiques. Nous ignorons par exemple depuis quand elle était affranchie lors de son premier mariage, et les règles sur le délai de viduité sont particulièrement complexes.
} 
faux si l'on s'en tient aux dates figurant dans le document ${ }^{43}$. La dot de Zumurrud augmente sensiblement à chacun de ses mariages, passant de 3 «dinars or» lors de son premier mariage, à 6 dinars dans le troisième. Qu'en est-il du montant de la dot dans les autres contrats à notre disposition ? Comment peut-on connaître la valeur réelle des montants cités et savoir quelle utilisation pouvait en faire l'épouse $?^{44}$

La mention de la dot, de la somme restante ou des montants perçus par les femmes au cours de leur vie maritale dépasse le seul cadre des contrats de mariage. D’autres types de documents : des quittances établies par l'un ou l'autre des époux, des reconnaissances de dettes, une conciliation devant un juge $(s ̦ l h)^{45}$ ou encore le contrat de vente d'une maison ou un waqf, rappellent le montant de la dot ou de la somme payable à terme. Le cas de Sitt alFakhr est intéressant à plus d'un titre : chrétienne, celle-ci réclame en effet devant un cadi musulman les 20 dinars restants de sa dot au moment de la signature de l'acte d'achat de la maison de son mari, située à Khaț̣ al-'Ațūf dans la ville du Caire. Elle demande que la somme soit alors déduite du prix d'achat total qui est de 64 dinars, et elle indique vouloir par la suite constituer la maison en waqf dans un but caritatif ${ }^{46}$.

\section{Des exemples concrets}

Pour cerner l'objet de cette étude, analysons un échantillon de documents datés afin de comparer les montants cités et d'avoir une meilleure connaissance de la valeur réelle de la somme versée.

L'exemple du contrat de mariage inédit ${ }^{47}$ d'une jeune fille impubère, Sayyidat al-Kull retient notre attention. Signé en Ifrīqiyā dans la première décade du mois de rajab de l'an

\footnotetext{
$43 \quad$ Voir d'autres exemples tirés de la littérature biographique dans Rapoport, Marriage, Money and Divorce in Medieval Islamic Society (Cambridge, Cambridge University Press, 2005), 62-6.

44

45 Dans ce document non daté, probablement rédigé entre 100/718 et 200/815, l'épouse, Sakīna, parvient à un arrangement avec son mari Abū Sulaymān pour obtenir le reste de sa dot. Ce dernier lui paye la somme due (ard̄āha), soit 30 dinars. Voir Raif G. Khoury, Chrestomathie de Papyrologie Arabe-Documents relatifs à la vie privée, sociale et administrative dans les premiers siècles islamiques (Leyde, E.J. Brill, 1993), II-2, notice $\mathrm{n}^{\circ} 19$. Ce document, conservé dans le fonds du Monastère Sainte Catherine au Sinaï a été édité par Lahcen Daaif dans la base de données CALD (Sinaï 313).

47 Document sans numéro d'inventaire, conservé dans le musée d'art islamique de Raqqāda (Kairouan), édité par Moez Dridi, «Un contrat de mariage sur parchemin d'une fille impubère en
} 
621/1224, il fait état d'une dot de cinquante-cinq dinars-dirhams d'argent frappé (sikkiyya $)^{48}$. Que représente une telle somme dans l'Ifrīqiyā de la première moitié du VII $/$ XII siècle ?

D'autres contrats rédigés dans cette région à la même époque nous donnent un ordre de grandeur : une dizaine d'années plus tard en effet, au mois de sha'bān 632/avril 1235, une résidence d'agrément (burj) est vendue dans les alentours de la ville de Kairouan ${ }^{49}$ pour un montant total de vingt-trois dinars-dirhams d'argent ${ }^{50}$. Au centre de cette même ville (hạạira), un terrain abandonné et sans construction a été vendu huit dinars en 636/1239 $9^{51}$. Un autre cas témoigne de la valeur importante de cette dot: en dhū 1-qa'da 625/octobre 1228, soit une quinzaine d'années après le mariage de Sayyidat al-Kull, une maison de trois pièces est achetée au centre de Kairouan pour la somme de 77 dinars en or. Avant de finaliser la vente, Fātima veuve de 'Abd al-Salām al-Qaysī, propriétaire de la dite maison, réclama la somme de 25 dinars, correspondant au montant $(a l-k \bar{a} l \bar{l})$ de sa propre dot, auquel s'ajoutait sa part dans l'héritage estimée à 22 dinars $^{52}$. À partir du corpus de CALD, on peut diversifier et multiplier les exemples d'une région à une autre et d'une époque à une autre. Une comparaison avec les contrats signés en Égypte permet d'affirmer que dans les actes dont nous disposons le montant de la dot est à l'évidence élevé ${ }^{53}$. Au $\mathrm{VIII}^{\mathrm{e}} / \mathrm{XIV}^{\mathrm{e}}$, un document rédigé au Caire et comprenant trois contrats illustre également l'importance du montant de la dot. Dans le premier contrat daté de 770/1369 $9^{54}$, on apprend que Khadīja bint al-marhūm Badr al-Dīn Husayn se marie pour la troisième fois avec le même homme, un militaire mamluk gradé dénommé Șayf al-Dīn Armanjī b. 'Abdallāh. Les époux s'étaient séparés la première fois

Ifrīqiyā pré-hafside», Les Cahiers de Tunisie, juin 2019, numéro spécial «Hommage au Professeur Mohamed Tahar Mansouri », 313-42.

$48 \quad$ Ainsi mentionné dans le document.

49 M. Dridi, «Un contrat d'achat pré-hafside d'une résidence d'agrément (burğ) dans la région de Kairouan ", dans Jaâfar Ben Nasr, Mourad Arar \& Nouri Boukhchim (dir.), Campagnes et archéologie rurale au Maghreb et en Méditerranée : actes du sixième colloque international, Kairouan, 14, 15 et 16 avril 2016, Tunis, 2018, 247-68.

Il s'agit là d'une monnaie de basse qualité contenant un pourcentage d'argent, voir G.C. Miles, «Dinar », $E I^{2}, 307-8$.

51 Document conservé au musée de Raqqada, en cours d'édition par M. Dridi. Un acte notarié au bas de ce document nous apprend que le terrain avait été remis à une certaine Jamīla b. 'Alī en tant que reliquat $(k \bar{a} l \bar{l})$ de sa dot après la mort de son mari. Elle a pu recevoir cette somme en héritage car son mari n'avait aucune descendance mâle du côté paternel ('așaba) susceptible d'hériter de ses biens. Ses seuls héritiers sont sa mère et ses deux sœurs. S.D. Goitein remarque que dans la communauté juive, le prix moyen des esclaves au Caire entre le $\mathrm{IV}^{\mathrm{e}} / \mathrm{X}^{\mathrm{e}}$ et le $\mathrm{VI}^{\mathrm{e}} / \mathrm{XII}^{\mathrm{e}}$ siècle était de 20 dinars mais qu'il y avait des exceptions. Ainsi, une esclave nūbiyya a été vendue 28 dinars en 1094 (I, 137), mais une rūmiyya 80 dinars en 995. Voir A Mediterranean Society :The Jewish Communities of the Arab World, 1, 139-40. Nous remercions Hmida Toukabri qui a attiré notre attention sur cet élément de comparaison. 1, 254-7, $\mathrm{n}^{\circ}$ 37. Ce contrat est conserve à Jérusalem, Musée du Ḥaram al-Sharīf, ms. 47. 
après une répudiation et la seconde par consentement mutuel. Tous deux possèdent la capacité juridique et la femme n'a pas d'autre tuteur que le juge. Dans ce contrat de mariage, Șayf alDīn s'engage à verser une nouvelle dot à son épouse et lui donne immédiatement 100 dinars. Au bas du document, le mari reconnaît en 774/1373, soit quatre ans plus tard, avoir versé à son épouse la somme de 200 dinars. À droite, et dans la marge, une troisième démarche devant le juge concerne de nouveau Khadija. Son mari étant décédé, elle s'est remariée en 781/1379 et elle conteste alors sa répudiation. Le juge lui donne raison au motif que le contrat de mariage n'avait pas été rédigé selon les règles exigées.

On le voit, dans l'Ifrīqiyā du $\mathrm{VII}^{\mathrm{e}} / \mathrm{XIII}$, , siècle comme au Caire au VIII $/ \mathrm{XIV}^{\mathrm{e}}$ siècle, le montant de la dot est parfois très important, sans doute dans des milieux aisés. Cette somme permettait à l'épouse d'acquérir une maison, un lot de terrain, voire de construire sa propre maison ou d'exercer une activité commerciale rentable si elle souhaitait faire fructifier ses revenus et s'assurer des ressources constantes ${ }^{55}$.

Les informations contenues dans les contrats concernant la dot et son montant nous font entrer dans la vie conjugale et nuancent le discours classique sur la nature du contrat de mariage et le rôle de la dot. On a vu que des négociations autour de la dot avaient lieu en permanence entre les époux et les membres de leur famille au cours du mariage: la détermination du montant versé au moment du contrat, les versements ultérieurs et le reliquat faisaient l'objet de discussion. La dot était conservée par l'épouse, investie dans des achats immobiliers, dans des opérations commerciales ou pour rembourser des dettes. Les contrats dont nous disposons donnent ici une toute autre image du mariage que celle de la simple analogie à un contrat de vente ou un louage de service.

\section{Quand les femmes imposent leurs conditions}

Le Coran, conforté par des hadiths, affirme en deux circonstances que «les hommes ont autorité sur les femmes» (IV : 34) et que «les hommes ont une prééminence sur elles (II : 228) ». La dimension monétaire du mariage suppose un rapport d'autorité et une certaine tutelle de la part du mari, ce qui a des répercussions sur la vie de couple. Néanmoins, l'exercice de cette prééminence est à nuancer par la complicité que l'on devine à la lecture des contrats rédigés par les époux au cours de leur vie commune.

55 Yossef Rapoport, «Matrimonial Gifts in Early Islamic Egypt », Islamic Law and Society 7/1 (2000) : 1-36. 
En plus des conditions de validité exigées à l'unanimité par les juristes - dot ou présence des témoins - des conditions supplémentaires ont en effet été introduites, dès le milieu du $\mathrm{III}^{\mathrm{e}} / \mathrm{IX}^{\mathrm{e}}$ siècle en Egypte, dans l'empire mamelouk et en Ifrīqiyā (VII $/ \mathrm{XIII}^{\mathrm{e}}$ ), ainsi qu'en témoignent les documents.

Une remarque linguistique et structurelle s'impose avant de traiter le rapport d'autorité entre époux. Au début de chaque contrat, la femme est mentionnée par les différents éléments constitutifs de son nom - patronyme incluant parfois le grand-père, nisba, shuhra - auxquels s'ajoutent une information d'ordre social ou la mention de son lieu de résidence. Mais à l'examen des documents, on constate que la manière de mentionner la femme évolue : on en parle comme d'une personne passive, ce qui se manifeste, sémantiquement parlant, par l'utilisation du pronom affixe (hā) comme dans aṣdaqahā, tazawajjahā, iyyāhā, etc., selon la modalité du ghă ib, donc à « la troisième personne », comme si elle n'était pas présente.

Nous avons, dans CALD, l'exemple de deux contrats de mariage dans lesquels le mari s'engage volontairement et en présence des témoins, à n'avoir qu'une seule épouse ${ }^{56}$. Le même type de contrats existe en Ifrīqiyā où il est connu sous le nom al-șadāq al-qayrawān̄ $\bar{l}^{57}$. La formule juridique, qui varie d'un contrat à un autre, se présente généralement sous la forme: sharața 'alā nafsihi. Nous trouvons aussi l'expression alzama dont le sens linguistique n'a pas la même portée juridique. Dans ces cas, le mari, à son tour passif sur le plan linguistique, s'engage librement à ne pas prendre une nouvelle épouse, qu'il s'agisse d'une femme libre ou d'une esclave, sans le consentement de sa première femme et aussi longtemps qu'il sera avec elle ${ }^{58}$. En cas de non-respect de cet engagement, l'épouse mentionnée dans le contrat a le droit de lui imposer de divorcer de la seconde.

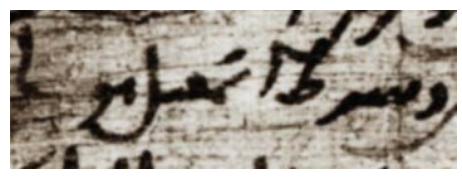

Le Caire, Dār al-kutub, ms. 159 $259 / 873$

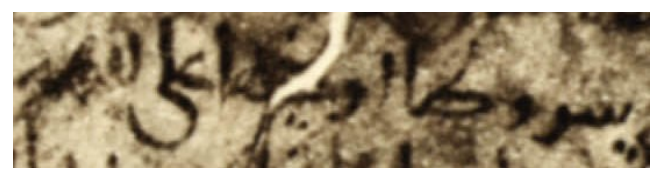

Le Caire, Dār al-kutub, ms. 121 279/892

Voir les deux contrats de mariage signés à Ashmūn, l'un en 259/873, l'autre en 279/892: Grohmann, Arabic papyri (Le Caire, Egyptian Library Press, 1934), 1, 67-8 et 85-8.

Muḥammad b. 'Aẓ̌ūum, Risālat al-tamlīk, éd. Muḥammad al-Tāhir al-Rizqī (Riyad : Maktabat alRushd, 1998). Mohammed Hocine Benkheira, « Un libre peut-il épouser une esclave ? Esquisse d'histoire d'un débat, des origines à al-Shāfi 'ì (m. 204/820)», Der Islam 84/2 (2007) : 243-355. 
Parfois, et pour alléger le poids de cette contrainte, une expression est ajoutée qui explique les raisons de ces conditions inhabituelles que le mari concède à sa future épouse : «pour gagner son affection et lui procurer de la joie» (istijlāban li-mawaddatihā wataqammunan li-masarratihā $)^{59}$.

Dans les contrats de mariage, les épouses imposent de multiples conditions lors de la rédaction (shurūt fì-l-nikāh). Elles obligent par exemple leur mari à habiter avec elle, dans leur propre maison, dans leur pays, ou encore à ne pas s'absenter plus de six mois ${ }^{60}$. Quelques-unes, issues d'un milieu aisé, ajoutent des conditions en lien avec leur situation matérielle: elles demandent à leur mari de mettre à leur disposition au moins le même nombre de serviteurs que dans la maison familiale où elles ne faisaient aucune tâche domestique (mimman lā takhdimu nafsahā ${ }^{61}$. Elles exigent parfois d'avoir une certaine liberté, notamment de pouvoir rendre visite à leur famille. Plus insolite dans les contrats est la mention du renouvellement de leur garde-robe, chaque année ou bien suivant les saisons, une pour l'été et l'autre pour l'hiver ${ }^{62}$. La présence de ces clauses dans les contrats a bien sûr pour corollaire la possibilité pour les femmes de déposer une requête devant un juge si elles n'étaient pas respectées. Ce dernier peut alors contraindre le mari à exécuter son obligation, ou bien dissoudre le mariage (faskh). Les épouses avaient ainsi, en pratique, l'équivalent d'un droit de répudiation, privilège accordé dans le Coran, aux hommes seuls. Certes, cette prérogative ne pouvait s'exercer que devant un juge et si l'époux manquait à ses obligations contractuelles. C'est la raison pour laquelle les femmes introduisaient des clauses additionnelles dans leurs contrats de mariage.

À ce stade, se pose une question d'ordre juridique : les juristes et les juges tiennent-ils compte des conditions que les maris s'imposent dans les contrats de mariage ? Leurs avis et jugements ont-ils varié selon les cas ? Y a t-il un seuil au-delà duquel les conditions introduites par les femmes ou leur représentant légal perdent leur valeur juridique? Les

$59 \quad$ Voir le document d'al-Andalus signé le 3 ramaḍān 928/27 juillet 1522. Conservé à Madrid, Bibliothèque nationale, 4908 (GR 72), il est édité par Hoenerbach, dans Spanisch-Islamische Urkunden (Berkeley, Los Angeles, 1965), 1, 185-6, n 12. Voir aussi Aḥmad b. Mughīth al-Ṭulayțulī, al-Muqni 'fì 'ilm al-shurūt (Beyrouth, Dār al-kutub al-'ilmiyya, 2000), 16. L'expression fait ici référence au Coran : XXX, $21:$ : Il a établi l'amour et la bonté entre vous ». Cette condition est stipulée dans ce même contrat conservé à Madrid, Bibliothèque nationale, 4908 (GR 72).

61 Al-Ṭulayțulī, al-Muqni' fì 'ilm al-shurūṭ (Beyrouth, Dār al-kutub al-'ilmiyya, 2000), 17.

62 Voir les travaux de Nelly Hanna sur l'époque ottomane, "Marriage among merchant families in seventeenth-century Cairo », dans Women, the family and divorces laws in Islamic history, éd. A. Sonbol (Syracuse, N.Y., Syracuse University Press, 1996), 143-54. 
opinions des juristes sont en réalité partagées. Les hanbalites rejettent catégoriquement ce type de conditions et contestent la validité des contrats de mariage qui les insèrent ${ }^{63}$. Ils estiment que le mari a été contraint de les accepter. Il arrive ainsi qu'un époux déclare devant le juge qu'il a consenti à ne pas se remarier à la condition tacite que sa femme ne lui réclamerait pas le paiement du reliquat de sa dot. Dans l'école malikite, certains juristes opèrent une distinction entre le contrat de mariage et les conditions additionnelles : le mariage est selon eux valide mais les conditions ne le sont pas (al-sharṭ bātil wa-l-nikāh șaḥịh) ${ }^{64}$, quel que soit l'auteur des ajouts, le mari ou son épouse.

L'opposition de ces juristes repose principalement sur deux arguments. Le premier, le plus important, est le fait qu'empêcher un homme d'avoir une autre épouse est contraire à la volonté divine : «Épousez, comme il vous plaira, deux, trois ou quatre femmes » ${ }^{65}$. D'après le second argument, ces conditions peuvent nuire à la deuxième épouse qui, ignorant les conditions posées par la première, s'engage en toute bonne foi. Elle risque alors de se retrouver divorcée sans raison juridique valide, ce qui est injuste vis-à-vis d'elle, et lui cause un préjudice (darar) sur le plan personnel et social.

Dans leur majorité cependant, les juristes reconnaissent la validité des conditions ajoutées par l'épouse dès lors que les éléments fondamentaux (arkān) du mariage sont présents : dot, tuteur, consentement mutuel et témoins. Ces clauses sont d'ailleurs fréquemment citées et explicitées dans les manuels de shurūt. C'est le cas, entre autres, de celui d'al-Jazīrī ${ }^{-66}$.

Dans les documents d'al-Andalus, pour éviter tout malentendu, le mari ou le notaire ajoutent une phrase clarifiant la nature des clauses incluses dans le contrat de mariage : «le mari s'est soumis à l'ensemble des conditions habituelles mentionnées dans le manuel notarié

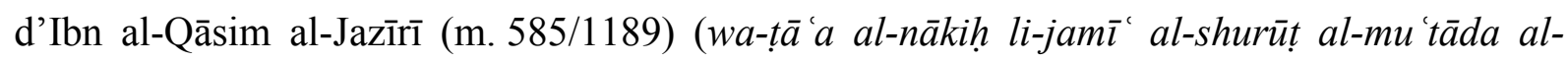
musammāt fì kitāb ibn al-Qāsim al-Jazīrî̀) ». La phrase débute ici par le verbe țā'a qui veut

\footnotetext{
63 Parmi les premiers juristes, al-Awzā $` \overline{1}(\mathrm{~m} .157 / 773)$ se fonde sur une parole prophétique pour dire que les stipulations écrites dans le contrat de mariage doivent être respectées (yuwaffā bihā) à condition qu'elles n'interdisent pas ce qui est licite (yuharim haläl) et ne modifient pas une obligation religieuse (yughayyir wājib) : al-Ṭulayțulī, al-Muqni' fì 'ilm al-shurūt, 25.

64 Muhammad b. Saḥnūn, Kitā̄b al-ajwiba (Beyrouth, Dār Ibn Hazm, 2005), 147.

65 Coran, IV : 3.

66 'Alī b. Yaḥyā al-Jazirī, al-Maqșad al-maḥmūd fì talkhīṣ al-'uqūd, éd. Asunción Ferreras (Madrid, Consejo Superior de Investigaciones Científicas, Instituto de cooperación con el mundo árabe, 1998).
} 
dire obéir, se soumettre à, être à la disposition de. Dans la plupart des contrats, on rencontre le verbe qabila qui signifie accepter de bon gré, agréer, accueillir, consentir ${ }^{67}$.

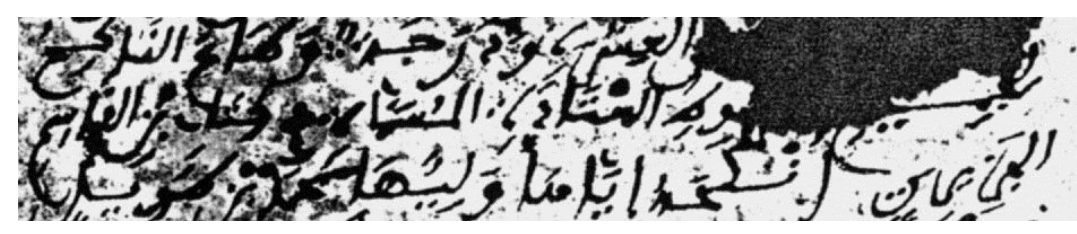

Madrid, Bibliothèque nationale, ms. 5452 verso, 908/1503

Note: Édité par Hoenerbach, dans Spanisch-Islamische Urkunden,

Berkeley, Los Angeles, 1965), 2, 176-7, $\mathrm{n}^{\circ} 10$.

Ces documents sont précieux car leur usage et la polémique qu'ils ont suscitée entre les juristes permettent de cerner plus précisément la situation matrimoniale des femmes dans la société musulmane médiévale. Les notaires ont en effet largement inséré dans les contrats de mariage les conditions voulues par les épouses et leur entourage, notamment leur tuteur. Elles sont supposées leur garantir des droits supplémentaires et restreindre ceux de leur mari. On en déduit que la pratique du droit est novatrice par rapport au discours normatif qui a cours dans le milieu juridique de l'époque car si les documents rédigés intègrent des conditions librement acceptées par les deux parties, c'est à l'évidence pour qu'elles soient appliquées. Lorsque ce n'était pas le cas, les femmes n'hésitaient pas à se rendre devant un juge et obtenaient gain de cause. On le voit dans la littérature juridique comme dans les documents, même si les causes du divorce y sont rarement mentionnées ${ }^{68}$.

\section{Les règles de conduite conjugales}

La lecture des contrats de mariage nous introduit dans l'univers familial : le mari dans son rapport à sa propre famille et les époux dans leur rapport avec la famille élargie et, au-delà, avec la société. Ces relations se compliquent par le fait qu'elles sont déterminées par un rapport au droit et à la religion et par un lien à la société. Dans un même contrat, l'idéal lointain se confond avec le vécu matériel, le commun avec le privé, l'immédiat avec la durée. Afin de comprendre ces dimensions, revenons à l'engagement contractuel.

Le mariage, on le sait, met l'accent sur la valeur temporelle qui le caractérise, comme le paiement de la dot. Le mari doit également ('alayhi) assurer à sa femme les dépenses

\footnotetext{
67 Dans la base CALD, le terme qabila est très majoritairement utilisé en Orient comme en Occident : 36 fois dans 27 documents, alors que ța 'a n'est présent que dans 3 documents. Voir le sens étymologique des termes dans A. de Biberstein Kazimirski, Dictionnaire arabe-français, 2 vol., Beyrouth, 2004). demander le divorce pour non respect des conditions figurant dans le contrat.
} 
nécessaires à la vie courante et il a l'obligation, même en cas de conflit, de reprendre sa femme d'une manière convenable ou bien de la renvoyer décemment (tasrīh bi-iḥsān ${ }^{69}$. Néanmoins, la dimension spirituelle est elle aussi bien présente. Accomplir la moitié de la religion (niṣf al-dīn) par le mariage, ainsi que le qualifie le Prophète, est une valeur « théologique » dans la mesure où cela permet au croyant de cheminer sur la voie du Salut. La quête du bonheur et de la paix intérieure que le couple s'efforce d'atteindre ici-bas lui permet de gagner l'au-delà ${ }^{70}$.

Quelles sont les notions et les formules employées par les juristes et les notaires concernant la bonne entente entre époux ? Et comment les époux s'engagent-ils au respect l'un de l'autre dans les contrats ? Nous ne disposons malheureusement d'aucun document écrit pendant les deux premiers siècles de l'hégire. Les plus anciens contrats de mariage, fragmentaires, conservés jusqu'à nos jours, remontent à la première moitié du III ${ }^{\mathrm{e}}$ siècle $^{71}$. Ils ne contiennent aucun élément concernant les rapports entre les époux. Ce vide chronologique et cette carence documentaire nous empêchent d'en tirer des conclusions. Quelques décennies plus tard, les contrats commencent à accorder une place aux recommandations visant à assurer à l'épouse un traitement spécifique, en lien avec les règles élaborées par le $f i q h^{72}$. Nous trouvons ainsi, dans un document écrit au mois de shawwāl de l'an 264/juin 878, la formule «entretenir de bon rapports» (husn al-ṣuhba $)^{73}$ et dans un autre, adopter «un bon comportement selon l'usage » (al-mu' ‘̄shara bi-l-ma 'rūf $)^{74}$.

\footnotetext{
$69 \quad$ Coran, II : 229.

70 Voir l'ouvrage de 'Alī Harb, al-Hubb wa-al-fanā' : al-mar'a al-sakīna al- 'adāwa (Beyrouth : al-Dār al'arabiyya li-1-'ulūm nāshirūn, rééd. 2014), 37-47.

71 Conservé au musée du Louvre, le second document, daté de 252/866 est édité par Yūsuf Rāghib «Marchands d'étoffes du Fayyoum au III $/ I X^{e}$ siècle, Les actes des Banū 'Abd al-Mu'min, Supplément aux Annales islamologiques 1 (Le Caire, IFAO, 1982).

72 À la même époque ( $\mathrm{III}^{\mathrm{e}} / \mathrm{IX}^{\mathrm{e}}$ siècle), le traditionniste sunnite al-Nasā' 1 consacre à cette question une section complète de ses Sunnan al-kubrā, éd. Aḥmad Shams al-Dīn (Beyrouth, Dār al-kutub al-'ilmiyya, 2005).

73 L'expression hush al-ṣuhba est présente dans 30 contrats de mariage. Une formule semblable est présente dans un contrat qui remonte à 945 au sein de la communauté juive karaïte : voir Karen Bauer, «A note on the relationship between Tafsìr and common understanding with Reference to Contracts of Marriage », dans Islamic Cultures, Islamic Contexts. Essays in Honor of Professor Patricia Crone, éd. Sadghi Behnam et alii (Leyde, Brill, 2015), 97-111, voir 108.

74 On trouve la seconde dans Levi Giorgio Della Vida, Arabic Papyri in the University Museum in Philadelphia (Pennsylvania), XXV (Rome, Accademia nazionale dei lincei, 1981), 47-48, notice $\mathrm{n}^{\circ} 27$.
} 


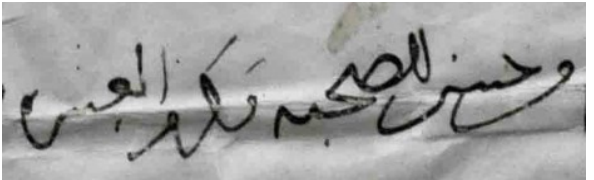

Kairouan, Musée Raqqada ms. 01-06

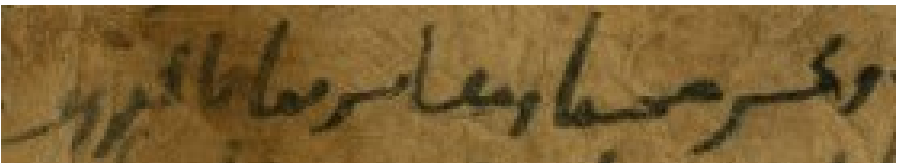

University of Utah, Salt Lake City, ms. 0791

Document conservé dans la base CALD, en cours d'édition.

Certes, le texte du contrat rappelle souvent une évidence coranique : l'époux a une prééminence sur son épouse (wa-daraja $z \bar{a} ' i d a^{75}$ ). Mais les notaires ajoutent que le mari doit craindre Dieu par égard pour l'épouse, rendre agréable sa compagnie et adopter une conduite conforme au bon usage. Les expressions se diversifient avec un même but : le devoir pour le mari d'entretenir avec sa femme de bonnes relations et des rapports harmonieux (jamīl al'ishra/karam al-ishra). L'influence de la religion est aussi présente dans l'injonction faite aux femmes de se comporter de même, suivant le précepte : «Les femmes ont des droits équivalents à leurs obligations et conformément à l'usage » (lahunna mithlu alladhī 'alayhinna bi-l-ma $r u \bar{u} f)^{76}$. Cette dernière notion est la clé de voûte qui détermine le type de relation entre les époux.

Les expressions à connotation religieuse et les exhortations morales trouvent donc leur origine dans le texte coranique et dans le hadith. Une phrase vient parfois l'expliciter: «Ainsi que Dieu l'a ordonné et d'après l'exemple de la tradition de l'envoyé de Dieu » (kamā amarahu Allāh et 'alā mā maḍa min sunna ri rasūl Allāh). Elles sont intégrées avec le temps dans les contrats de mariage, à l'instar des conditions imposées par les épouses et en même temps que se développe la science du tafsīr et celle du hadith ${ }^{77}$. Le fiqh et la science des shurūt commencent aussi à se constituer sur des bases coraniques et prophétiques dès la deuxième moitié du $\mathrm{III}^{\mathrm{e}} / \mathrm{IX}^{\mathrm{e}}$ siècle. Un passage dans certains contrats traduit l'obligation pour l'homme d'être pieux envers Dieu, très grand «pour elle» (an yattaqī Allāh al-'aẓīm), expression qui rappelle la tradition prophétique «Soyez pieux envers Dieu pour les femmes,

\footnotetext{
75 Coran, II : 228. Cette notion a été développée par Abdelouahad Bouhdiba, La sexualité en Islam (Paris, PUF, 1982), dans le chapitre III « Féminin éternel ».

Coran, II : 228. Selon Michael Cook - Commanding Right and Forbidding Wrong in Islamic Thought (Cambridge, Cambridge University Press, 2000) 15 - ma'rūf n'est pas un terme juridique en soi, il vient «s'ajouter à une autre action juridique » (performing a legal other action).

77 K. Bauer, «A note on the relationship between Tafsìr and common understanding with Reference to Contracts of Marriage » (Leyde, Brill, 2015).
} 
car vous les avez prises dans la sauvegarde de Dieu » (fa-attaqū Allāh fì al-nisā' fa-innakum akhadhtumuhunna bi-amānat Allāh $)^{78}$.

Les formules sont nombreuses qui enjoignent les époux à mener une vie de couple sereine : avoir une union d'affection (jam 'al-ulfa), ou maintenir la concorde (iṣlāh dhāt albayn), faisant écho au passage coranique așliḥu dhāt baynikum ${ }^{79}$. L'expression al-muwāsāt fì dhât al-yad a deux interprétations : la première est de prêter assistance à quelqu'un sur le plan financier, la seconde consiste à partager sur un pied d'égalité biens et revenus. Les deux ont un seul et même but : que les époux se prêtent une assistance mutuelle. Quant à la formule hifz li-l-ghayba, elle est rarement employée. Il s'agit là encore d'une adaptation du verset coranique : «Les femmes vertueuses sont pieuses : elles préservent dans le secret ce que Dieu préserve » (hâfizāat li-l-ghayb $)^{80}$. On la rencontre uniquement dans deux contrats de mariage signés au milieu $\mathrm{du} \mathrm{V}^{\mathrm{e}} / \mathrm{XI}^{\mathrm{e}}$ siècle en Égypte ${ }^{81}$. Les femmes ont le devoir de veiller, en l'absence de leur mari, sur ce qui doit être gardé : la maison et ses biens, sa personne et en particulier son corps afin d'épargner à son mari la honte de l'adultère. Interrogeons-nous à présent sur l'influence de la religion dans la rédaction des contrats. A-t-elle empêché les membres des minorités religieuses de recourir aux notaires dans la société musulmane?

\section{Quand les femmes juives et chrétiennes recourent au droit musulman}

On a vu précédemment l'exemple de la requête devant le juge de la chrétienne Sitt al-Fakhr, au moment de l'achat de la maison de son mari défunt au Caire. Pourquoi les membres des communautés juive et chrétienne, en particulier les femmes, signent-ils des actes notariés de droit musulman et recourent-ils à un juge en présence de témoins eux aussi musulmans ?

On sait que le droit musulman préconise aux membres des minorités religieuses de régler leurs litiges entre eux, dans leurs propres tribunaux, leur reconnaissant de ce fait une

\footnotetext{
78 Hadith rapporté par Muslim dans Șaḥ̄ḥ, Kitāb al-Birr, éd. 'Abd al-Bāqī, 5 vol. (Le Caire, Dār Ihyā̄' al-kutub al-'arabiyya, 1955, 4, 1974. Voir par exemple le contrat signé en Égypte en 413/1023 : Alia Hanafi, « Two Contracts of Marriage of Papyrus Collections in Cairo and Copenhagen », dans Atti del XXII congresso internazionale di papirologia, Firenze, 23-29agosto 1998, Istituto papirologico " $G$. Vittelli”, 1 (Florence, 1998), 571-84, éd., 577.

Coran VIII : 1 .

Coran, IV, 34.

L'un est daté de 452/1060, voir Yūsuf Rāghib, Transmission de biens, mariage et répudiation à Uqlūl, 45-8, l'autre de 444/1052: voir Raif G. Khoury, Papyrologische Studien zum privaten und gesellschaftichen Leben in den ersten islamischen Jahrhunderten (Wiesbaden, Harrassowitz Verlag, 1995), «Codices Arabici Antiqui V », notice $n^{\circ} 1$.
} 
autonomie juridique $^{82}$. Mais les contrats dont nous disposons dévoilent parfois une toute autre réalité. Il arrive en effet que les dhimmīs choisissent de se rendre devant un juge musulman pour faire valider un contrat de mariage ou régler un litige. L'analyse de ces documents juridiques permet donc de dépasser les stéréotypes et de réfléchir aux raisons de ce choix. Que peut apporter à une femme juive ou chrétienne un contrat de mariage formulé suivant les règles et les conditions du droit musulman ?

Sans perdre de vue que la majorité de la population était non musulmane pendant les trois ou quatre premiers siècles de l'Islam, on constate que le fiqh a délimité le champ d'action des membres des autres religions qui prenaient part à la dynamique économique et sociale, dans des conditions susceptibles de préserver leurs droits, voire leurs intérêts. Prenons le cas d'un contrat de mariage entre deux époux de religion copte, rédigé en 336/948 au Caire et au bas duquel soixante témoins, chrétiens et musulmans, apposèrent leur signature. Le mari, Theodore, b. Samawīl, un diacre chargé de la distribution des aumônes, s'y engage à payer la somme de quatre-vingt-dix dinars en dot à Dbêlī Adāy, fille d'un prêtre copte ${ }^{83}$. Dans un autre contrat, une chrétienne Elena bint Antanās, épouse de Qīriqe b. Theodore, reconnaît en dhū-1 hijjja 378/avril 989, en présence de deux témoins musulmans, 'Alī b. Ja'far et alḤasan b. Aḥmad, avoir reçu de son mari, lui aussi de confession chrétienne, le reste de sa $\operatorname{dot}^{84}$. Dans la communauté juive, citons un mariage mixte entre Mikhā’̄̄l b. Ishāa b. Sa‘īid alNașranī, courtier chrétien (simṣār), et une jeune fille juive Shaqrā' bint Samāwil alYāhūdiyya ${ }^{85}$ On le voit, les membres de ces deux communautés préféraient parfois signer leur contrat devant un juge musulman, ce pour maintes raisons. Dans le cas des membres de la communauté juive, une telle démarche présentait des avantages, tant sur un plan pratique que financier, notamment pour les habitants des régions rurales dans lesquelles il n'y avait pas de rabbin. Dans les affaires litigieuses, les différends étaient alors réglés sur place auprès du juge musulman, sans attendre l'avis ou l'accord d'un rabbin, souvent éloigné, lequel avait l'obligation d'examiner tous les documents et pouvait demander d'entendre les témoins. Si un désaccord survenait entre les époux, au sujet de la dot ou d'un héritage par exemple, les

\footnotetext{
82 J. Schacht écrivait à ce propos que « la juridiction du qadi ne s'étendait qu'aux seuls musulmans ; les populations non musulmanes soumises gardaient leurs propres institutions juridiques traditionnelles, y compris les tribunaux ecclésiastiques (ou rabbiniques) ». Voir Esquisse d'une histoire du droit musulman (Paris, Librairie Orientale et Américaine, 1952), 21. Nabia Abbott, « Arabic Marriage Contracts among Copts », dans Zeitschrift der Deutschen Morgenländischen Gesellschaft, 95 (Leipzig, F.A. Brockhaus, 1941), 59-81, plus particulièrement 77-81. Ibid., 77-8.

Document conservé à la bibliothèque universitaire de Cambridge, en cours d'édition.
} 
tribunaux rabbiniques ou ecclésiastiques n'avaient pas les moyens de mettre leur jugement en exécution. Ils avaient en effet l'obligation, dans certains cas, de s'en référer aux autorités musulmanes. Recourir au préalable à un notaire musulman pour rédiger un contrat était donc souvent plus facile et permettait de faire exécuter les décisions de droit ou de parvenir à la résolution d'un conflit plus rapidement.

Le droit musulman se présentait ainsi, pour les minorités religieuses, comme une alternative, en mettant à leur disposition non seulement l'appareil jurisprudentiel musulman, mais aussi une force de police (shurțā) capable d'exécuter les décisions du juge. De ce fait, les différentes composantes de la société étaient toutes placées sur un pied d'égalité et les minorités religieuses partageaient de nombreuses conceptions avec leurs contemporains musulmans au sujet du mariage et des relations entre époux. En recourant au droit musulman, ils étaient ainsi liés par une communauté de droit, avec des conditions, des engagements et des devoirs valables pour tous.

\section{Conclusion}

Ces dernières décennies, les écrits sur l'histoire de la famille, du couple, de la femme et de la sphère privée ont pris de l'ampleur, influencés par la micro-histoire. Deux courants se sont développés, donnant lieu à des controverses : celui de l'«histoire des femmes » et plus récemment celui de $l^{\prime}$ « histoire du genre ».

En marge de ces débats, l'analyse des documents de la pratique juridique en Islam médiéval ouvre des perspectives de recherche nouvelles, tant pour l'histoire institutionnelle, juridique, économique que pour l'histoire sociale. Le corpus dont nous disposons est sans équivalent et c'est la richesse de son contenu que nous avons voulu faire découvrir ici. Les actes notariés permettent en effet d'aborder autrement le droit de la famille en diversifiant les approches. Le statut matrimonial des femmes, musulmanes ou non, à partir des contrats, est encore peu étudié ${ }^{86}$. Or les femmes, quelles que soient l'époque et la région du dār al-islām concernées, ont usé de la possibilité qui leur était donnée de faire rédiger des contrats à différentes occasions de leur vie : mariages, séparations, achats et ventes de biens, dons en

$86 \quad$ Voir l'article de Mounira Chapoutot-Ramadi, «Femmes dans la vie mamlūke », Journal of Economic and Social History of the Orient 38/2 (1995), 145-64. Elle y montre le décalage entre pratique juridique et réalité quotidienne de la femme dans l'Égypte mamelouke. 
waqf. Elles conservaient ces documents et se rendaient devant les cadis pour faire respecter leurs droits.

Nous avons notamment mis l'accent sur des aspects méconnus dans les contrats de mariage : l'importance des éléments décrivant les qualités de l'épouse, la valeur de la dot mais encore les conditions additionnelles visant à lui assurer une vie matérielle plus confortable, ou l'interdiction formulée à l'endroit du mari de prendre une seconde femme. Mais le mariage en Islam n'est pas seulement un contrat, ainsi qu'en témoignent les nombreuses clauses sur la bonne entente entre les époux : c'est une institution qui leur impose une vie commune en harmonie ici-bas afin de garantir pour l'un et l'autre une vie heureuse dans l'au-delà. Nous avons évité de prendre position dans le débat qui met en confrontation le masculin et le féminin dans la société et analyse les deux identités marquées par un dualisme : dominant et dominé, oppresseur et opprimé ${ }^{87}$. À travers les documents juridiques de 1'Islam médiéval, notre objectif était au contraire d'éclairer le statut matrimonial de la femme dans le cadre d' « une histoire résolument relationnelle qui intègre la société toute entière ${ }^{88}$.
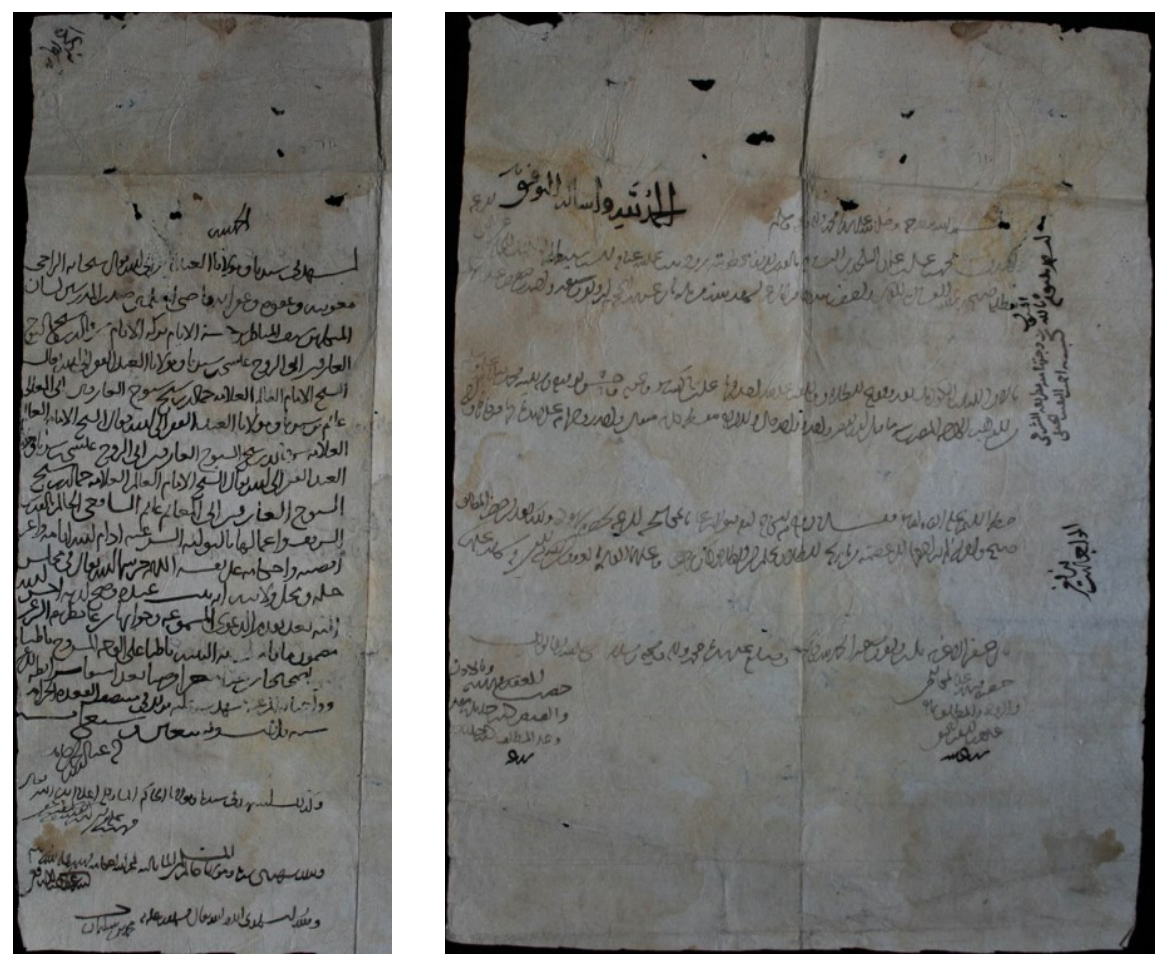

Les actes notariés de la vie maritale de Zumurrud Jérusalem, Musée du Ḥaram al-shārif, mss. 610 et 646

87

Ce que Françoise Héritier désigne par « valence différentielle des sexes », Masculin, Féminin. La pensée de la différence (Paris, Odile Jacob, 1996).

88 George Duby, Michelle Perrot, Histoire des femmes en Occident, 5 vol. (Paris, Plon, 1991-2), 1, préface. 


\section{Bibliographie}

\section{Sources}

al-'Asalī, Kāmal Jamīl, Wathā'iq maqdisiyya tārīkhiyya, 2 vol., Amman : Maṭba'at al-tawfīq, 1983-5.

al-Jazīrī, 'Alī b. Yaḥyā, al-Maqșad al-maḥmūd fì talkhịs al-'uqūd, éd. Asunción Ferreras, Madrid: Consejo Superior de Investigaciones Científicas, 1998, «Fuentes arábicohispanas, $23 »$.

al-Nasā' $\overline{1}$, Aḥmad b. Shu'ayb, Sunnan al-kubrā, éd. Aḥmad Shams al-Dīn, Beyrouth : Dār alkutub al-'ilmiyya, 2005.

al-Samarqandī, Abū Nașr Muhammad, Kitāb al-shurūṭ wa- 'ulūm al-șukūk, éd. M. Jāsim alHadīthī, Bagdad : 1987.

al-Sarakhsī, Muḥammad b. Aḥmad, Kitāb al-Mabsūț, éd. Muḥammad Rāḍī, Le Caire : Mațba'at al-Sa'āda, 1906-13, 30 t. en 15 vol..

al-Ṭulayțulī, Aḥmad b. Mughīth, al-Muqni' fì 'ilm al-shurūt, Beyrouth : Dār al-kutub al'ilmiyya, 2000.

El-Bokhârî, Les traditions islamiques, 4 vol., trad. O. Houdas, Paris, 1908.

Ibn 'Aẓẓūm, Muḥammad, Risālat al-tamlīk, éd. Muḥammad al-Tāhir al-Rizqī, Riyad : Maktabat al-Rushd, 1998.

Ibn Juzayy, Muḥammad b. Aḥmad, al-Qawānīn al-fiqhiyya, éd. 'Abd Allāh al-Minshāwī, Le Caire : Dār al-ḥadīth, 2005.

Ibn Qudāma, Muwaffaq al-Din 'Abdallāh b. Aḥmad, Le précis de droit d'Ibn Qudāma, jurisconsulte musulman d'école hanbalite né à Jérusalem en 541/1146, mort à Damas en 620/1223, trad. fr. par Henri Loust, Beyrouth, 1950.

Ibn Qutayba, 'Abd Allāh b. Muslim, Adāb al-kātib, éd. 'Alī Fā'ūr, Beyrouth : Dār al-kutub al'ilmiyya, 1988.

Ibn Saḥnūn, Muhammad, Kitāb al-ajwiba, Beyrouth : Dār Ibn Hazm, 2005.

Muslim, Șah̄̄h, Kitāb al-Birr, éd. 'Abd al-Bāqī, 5 vol., Le Caire : Dār Iḥyā' al-kutub al'arabiyya, 1955.

\section{Études}

Abbott, Nadia, «Arabic Marriage Contracts among Copts », dans Zeitschrift der Deutschen Morgenländischen Gesellschaft, 95, Leipzig : F.A. Brockhaus, 1941.

Ali, Kecia, Marriage and Slavery in Early Islam, Cambridge, Mass. : Harvard University Press, 2010.

Balandier, Georges, «Hommes et femmes ou la moitié dangereuse », Anthropologiques, Paris, PUF, 1974, 13-61. 
Bauer, Karen, «A note on the relationship between Tafsīr and common understanding with Reference to Contracts of Marriage », dans Islamic Cultures, Islamic Contexts. Essays in Honor of Professor Patricia Crone, éd. Sadghi Behnam et alii, Leyde : Brill, 2015.

Badinter, Elisabeth, Fausse route, Paris : Odile Jacob, 2003.

Benkheira, Mohammed Hocine, "Alliance, symétrie et difference des sexes. Un problème d'exégèse juridique : la prohibition de la belle-mère et de la belle-fille », Islamic Law and Society 13/2 (2006) : 153-207.

Benkheira, Mohammed Hocine, «Un libre peut-il épouser une esclave ? Esquisse d'histoire d'un débat, des origines à al-Shāfi '’̀ (m. 204/820) », Der Islam 84/2 (2007) : 243-355.

Benkheira, Mohamed Hocine, Gil'adi, Avner, Mayeur-Jaouen, Catherine, Sublet, Jacqueline, La famille en islam d'après les sources arabes, Paris : Les Indes savantes, 2013.

Bianquis, Thierry, La famille arabe médiévale, Bruxelles : Complexe, 2005.

Bouhdiba, Abdelouahad, La sexualité en Islam, Paris : PUF, 1982.

Bousquet, Georges-Henri, Précis de droit musulman, 2 vol., Alger : Maison des livres, 1935.

Chapoutot-Ramadi, Mounira, "Femmes dans la vie mamlūke », Journal of Economic and Social History of the Orient 38/2 (1995), 145-64.

Cook, Michael, Commanding Right and Forbidding Wrong in Islamic Though, Cambridge : Cambridge University Press, 2000.

Daaif, Lahcen, «La barā'a : réflexions sur la fonction et l'évolution de la structure de la quittance $\left(\mathrm{I}^{\mathrm{er}}-\mathrm{V}^{\mathrm{e}} / \mathrm{VII}^{\mathrm{e}}-\mathrm{XI}^{\mathrm{e}}\right.$ siècles) » Annales islamologiques 48/2 (2014) : 3-60.

Dietrich, Albert, Eine Arabische Eheurkunde aus der Aiyubidenzeit, Berlin : Vorgelegt in der Sitzung der Deutschen Akademie der Wissenschaften zu Berlin vom: 30.11.1950, 1952.

Dridi Moez, "Un contrat de mariage sur parchemin d'une fille impubère en Ifrīqiyā préhafside », Les Cahiers de Tunisie, juin 2019, numéro spécial : « Hommage au Professeur Mohamed Tahar Mansouri », 313-42.

Dridi Moez, « Un contrat d'achat hafside d'une résidence d'agrément (burğ) dans la région de Kairouan », dans Jaâfar Ben Nasr, Mourad Arar \& Nouri Boukhchim (éds), Campagnes et archéologie rurale au Maghreb et en Méditerranée : actes du sixième colloque international, Kairouan, 14, 15 et 16 avril 2016, Tunis, 2018, 247-68.

Duby, George et Perrot, Michelle, Histoire des femmes en Occident 5 vol., Paris : Plon, 19911992.

Dumézil, Georges, Mariages indo-européens, Paris, Payot, 1979.

Giorgio Della Vida, Levi, Arabic Papyri in the University Museum in Philadelphia (Pennsylvania), XXV, Rome : Accademia nazionale dei lincei, 1981.

Goitein, Shelomo Dov, A Mediterranean society: the Jewish communities of the Arab world as portrayed in the documents of the Cairo Geniza, 6 vol., Berkeley: University California Press, 1967-93.

Grohmann Adolf, Arabic papyri in the Egyptian library, Volume I : Protocols and Legal Texts with Twenty Plates, Le Caire : Egyptian Library Press, 1934. 
Hanafi, Alia, «Two Contracts of Marriage of Papyrus Collections in Cairo and Copenhagen », dans Atti del XXII congresso internazionale di papirologia, Firenze, 2329 agosto 1998, Istituto papirologico “G. Vittelli”, 1, Florence, 1998.

Hanna, Nelly, "Marriage among merchant families in seventeenth-century Cairo », dans Women, the family and divorces laws in Islamic history, éd. A. Sonbol, Syracuse, N.Y., Syracuse University Press, 1996.

Harb, 'Alī, al-Hubb wa-al-fanā' : al-mar'a al-sakina al-'adāwa, Beyrouth : al-Dār al'arabiyya li-1-'ulūm nāshirūn, rééd. 2014, 37-47.

Héritier, Françoise, Masculin, Féminin. La pensée de la différence, Paris, Odile Jacob, 1996.

Hoenerbach, Wilhelm dans Spanisch-Islamische Urkunden: aus der Zeit der Nasriden und Moriscos, Berkeley, Los Angeles : University of California Press, 1965.

Idris, Roger, «Le mariage en Occident musulman d'après un choix de fatwās médiévales extraites du « Mi'yār » d'al-Wanšarīsī », Studia islamica 32 (1970) : 157-67.

Kazimirski, A. de Biberstein, Dictionnaire arabe-français, 2 vol., Beyrouth, 2004.

Khan, Geoffrey, Arabic Documents from early Islamic Khurasan, Studies in the Khalili Collection, vol. V, Londres : The Nour Foundation, 2007.

Khoury, Raif G., Chrestomathie de Papyrologie Arabe-Documents relatifs à la vie privée, sociale et administrative dans les premiers siècles islamiques, Leyde : E.J. Brill, 1993.

Largueche Dalenda, Monogamie en Islam : l'exception kairouanaise, Tunis, Manouba: Centre de publication universitaire, 2011.

Little, Donald, A Catalogue of the Islamic Documents from al-Haram aš-Šarîf in Jerusalem, Beyrouth : 1984.

G.C. Miles, « Dinar », $E I^{2}, 1,307-8$.

Morand, Marcel, Etudes de droit musulman algérien, 2 vol., Alger : Typ. A. Jourdan, 1910.

Mouton, Michel et alii, Mariage et séparation à Damas au Moyen Age. Un corpus de 62 documents juridiques inédits entre 337/948 et 698/1299, Paris: Académie des Inscriptions et Belles Lettres, 2013.

Rāghib, Yūsuf, Transmission de biens, mariage et répudiation à Uqlūl, village du Fayyoum au $V^{e} / X I^{e}$ siècle, Le Caire, Cahier des Annales islamologiques 33, 2016.

Rāghib, Yūsuf, "Marchands d'étoffes du Fayyoum au III'/IX' siècle, Les actes des Banū 'Abd al-Mu'min, Supplément aux Annales islamologiques, 1, Le Caire : IFAO, 1982.

Rapoport, Yossef, Marriage, money and divorce in medieval Islamic society, Cambridge : Cambridge University Press, 2005.

Rapoport, Yossef, Matrimonial Gifts in Early Islamic Egypt », Islamic Law and Society 7/1 (2000) : 1-36.

Schacht, Josef, Esquisse d'une histoire du droit musulman, Paris : Librairie Orientale et Américaine, 1952.

Thung, Michael Arabische juristische Urkunden aus der Papyrussammlung der oesterreichischen Nationalbibliothek, Corpus Papyrorum Raineri XXVI, Leipzig: Generaldirektion der Oesterreichischen Nationalbibliothek, 2006. 